\title{
A Comparative Study on the Physical Quality (Lower Body Strength and Endurance) of Boys Under-17 Youth Football Development Project and Non-Athletes of the Same Age Group: The Case of Debre Markos Town
}

\author{
Fenta Bitew* \\ Department of Sport Science, Debre Markos University, Ethiopia
}

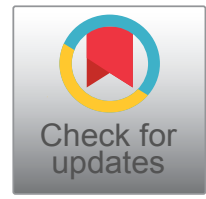

*Corresponding author: Fenta Bitew, Department of Sport Science, Debre Markos University, Debre Markos, Ethiopia, Tel: +251-922851373, Fax: +251-58771-1764

\begin{abstract}
Professional spends more time and efforts for improvement of athletic performance. The study was conducted for the comparison of physical qualities (lower body strength and endurance) of boys under-17 youth football development project participants and non-participants of the same age group at Debre Markos town. The research design was cross-sectional survey. The researcher selected 25 project participants by using simple random sampling and 25 non-athletes by using purposive sampling technique. The result of the test shows that project participants were better than non-participants in all three tests. Five football project participants squat test score found in average must do improve their lower body strength and 12-munits run test score found in marginal zone must do endurance activity. Five football project participants step test score found in above average score must do endurance activity.
\end{abstract}

\section{Keywords}

Strength, Endurance, Football, Physical qualities

\section{Introduction}

\section{Background of the study}

Cardiovascular fitness is important for all human beings irrespective of their age. According a given work may not be carried out if the required physical strengthen is not available. Fitness is the first and foremost things to enjoy the life fully. Regular physical activity: fitness and exercise are critically important for health and wellbeing of people of all whether they are par- ticipated vigorous exercise or some type of moderate health enhancing physical activity.

Testing an athlete's physical qualities is extremely important for evaluation process and control of group players of footballers. The physical attributes of under-17 youth football development project and non-athlete are measured in variety of ways in different test design. All coaches want to be sure that they are putting their best athletes in a game. According to [1] testing an athlete can help the coach determine the potential of players to play at certain position. Testing process include all areas of training such as strength and endurance that might reflects strength and weakness of the athletes and testing needs to be administered in an effective manner to ensure an accurate evaluation [2].

According to [3] a distance runner needs exceptional cardiovascular fitness and muscular endurance, while lineman in football needs exceptional strength for successes in sports. High performance levels of health-related physical fitness components are necessary over and above what the normal person needs to enhance health. A fit person is one who has well-adjusted to his environment, whose mind and body are in harmony and can meet the normal demands both mentally and physically without undue fatigue. Physical fitness is one of the basic elements which are essential for better performance in all competitive sports. 
[4] Also made a research on selected physical fitness components of state level male footballers. He found no significant difference on selected physical fitness components especially in muscular strength. But this study compares lower body strength and endurance. Attempt is made in this study of selected physical fitness variable among under-17 youth football development project players and Non-athlete in Debre Markos town. Based on the above points study was conducted the difference in selected basic physical qualities of lower body strength and endurance of boys' under-17 football development project and non-athletes of the same age in Debre Markos town.

\section{Statement of the problem}

Professional football is characterized by high physical qualities and frequent changes in exercise and density [5]. The physical fitness of players is one the crucial foundation which determines the efficiency of the lower body strength and endurance performance. The research has been got the chance to observe boys in under-17 youth football development project and non-athletes of the same age group in Debre Markos town.

Athletes' strength and endurance have developed and accustomed for each repeated work any kind of work and sport are demands strength and endurance. Lack of activities leads to lack of fitness which leads to the loss of strength and endurance. Therefore, the researcher was interested to conduct the research on the comparative study on the physical qualities lower body strength and endurance) of boys under 17 youth male football development project participants and non-athlete at Debre Markos town.

\section{Research questions}

The following research questions were raised to achieve the objective of the research.

1. Is there a significance difference between under-17 youth male football development project participants and non- athlete participants in lower body strength qualities of the same age?

2. Is there significance different between less than 17 youth football development project participant and non-athletes' participants in endurance of same age?

\section{Objective of the study}

General objective: The overall aim of the research is to compare the physical qualities (lower body strength and endurance) of male in under 17 youth football development project participant and non-athlete participant of the same age group at Debre Markos town.

\section{Specific objectives}

The following specific objectives were addressed:
1. To compare the physical qualities of lower body strength of under-17 youth football development project participant and non-athlete participants of the same age group.

2. To compare the endurance qualities between boys in under-17 youth football development project participants and non-athlete participants of the same age group.

\section{Significance of the study}

The research has the following significances:

1. The prime significance of this research would be for football development project players and non-athletes about their level of lower body strength and endurance.

2. The research would dig out problems and come with possible solutions for the problem.

3. The research would provide valuable highlights' about project participants and non-athletes for coaches and stakeholders.

4. Used as base for further studies on under 17 youth football development project specially to lower body strength and endurance.

\section{Methods and Materials}

\section{Study area and period}

The study has been conducted in Debre Markos town, located at North West of the capital city Addis Ababa with $300 \mathrm{~km}$ distance and $265 \mathrm{~km}$ south east of Bahir Dar; the capital of Amhara national regional stat. The town has $1380 \mathrm{ml}$ average annual rainfall and $\mathrm{min}$ imum and maximum temperature of $15{ }^{\circ} \mathrm{C}$ and $22^{\circ} \mathrm{C}$ respectively. The study period was in 2011E.C/2019GC.

\section{Research design}

Cross-sectional survey research design was employed. The research identifies and justifies the problem of comparative study of boys in fewer than 17 youth football development project and non-athletes of the same age group, due to lower body strength and endurance. Data was collected from primary source by testing athlete and non-athlete.

\section{Population of the study}

The targeted populations of the study were 75 . From these total populations 50 of them are boys in under-17 youth football development and 25 of them are non-athletes of the same age group.

\section{Sample size and sampling techniques}

The researcher selected 2 goal keepers, 8 defenders, 10 midfielders and 5 strikers a total of 25 under- 17 youth football development project by using simple random sampling techniques and also 25 non-athlete by using purposive sampling techniques of the same age groups. 


\section{Source of data \& data collection instrument}

Primary source of experimentation on result was a source of data. Each subjects of the participants in series of testing conducted by tester and assistant. The two category groups' lower body strength and cardiovascular endurance would be compared by squat, step and 12-minute run test.

\section{Data analysis}

The data scores from different testing results were analyzed and described by using performance testing methods. When the researcher tests the performance of the two category groups each select test method and score results were calculated by descriptive statistics of mean values and percentage.

\section{Ethical consideration}

Initially letter of permission was taken from Debre Markos University, College of Natural and Computational Science, especially Department of Sport Science and submitted to East Gojjam youth and sport affairs. Participants on the study were willing for the study. The researcher has been explained the purpose of the study for every participant and obtain information consent before beginning of the test. Moreover, culture and traditional value of all participants were taken to an account Table 1.

Squat test procedure: This test requires the athlete to complete as many squats as possible with no rest.; warm up for 5 minutes of athlete and none athlete; The athlete or non-athlete stand in front of the chair, facing away from it, with their feet shoulder width apart.; The athlete or non-athlete squats down lightly touching the

Table 1: Squat test standards for boys with age of 16.

\begin{tabular}{|l|l|}
\hline Score & Performance category \\
\hline Excellent & $>49$ \\
\hline Good & $44-49$ \\
\hline Above average & $39-43$ \\
\hline Average & $35-38$ \\
\hline Below average & $31-34$ \\
\hline Poor & $25-30$ \\
\hline Very Poor & $<25$ \\
\hline
\end{tabular}

Adopted from Concept of physical fitness for wellness $10^{\text {th }}$ edition, Charles B, et al. (2000) care with their sequence of movement until they are unable to continue and the assistant counts and records the number of successfully completed squats Table 2 .

Step test procedure: Warm up prior to exercise and step up and down on 12 inch bench for three minutes at a rate of 24 steps per minute. One step consists of four beats; that is "up with the lift foot up with the right foot, down with the lift foot, down with the right foot"; immediately after the exercise, sit down on the bench and relax. Don't talk. Locate your pulse or have another person locate it for you; 5 seconds the exercise ends, begin continuing your pulse. Count the pulse for $60 \mathrm{sec}-$ ond and your score is your 60 second heart rate Table 3 .

12-minute run test procedure: Locate an area where a specific distance is already marked, school truck or football field; use stopwatch or wristwatch to accurately time a 12-minute period; For best result warm up prior to test, and then run at a steady pace for the entire 12 minutes; determine the distance you can run in $12 \mathrm{~min}$ utes and depending up on your age, locate your score in rating chart.

Over all procedures: There are two major testing periods (First and second testing period). The first testing periods is at the third week of May and athletes are tested immediately. An athlete's score in squat, step test and 12-minute run test recorded during this testing period for both groups. The second test session began at the second week of Jun. Test scores are gathered in squat, step and 12-minute run test scored during this testing period for both groups. This is a very important testing session because it is the last testing session of the day wants to look at the athletes last testing session the athletes test scores over, then the first period testing scores, so the investigator then picked their personal best scores.

Table 2: Step test Standards in 60 second heart rate.

\begin{tabular}{|l|l|}
\hline Step test rating Standards \\
\hline Classification & $\mathbf{6 0}$ second heart rate \\
\hline High-performance zone & 84 or less \\
\hline Good fitness zone & $85-95$ \\
\hline Marginal zone & $96-119$ \\
\hline Low zone & 120 and above \\
\hline
\end{tabular}

Adopted from Concept of physical fitness for wellness $10^{\text {th }}$ edition, Charles B, et al. (2000)

Table 3: The 12-minutes run test score in meters.

\begin{tabular}{|l|l|l|l|l|}
\hline Men Age & \multicolumn{3}{l|}{} \\
\hline Classification & $\mathbf{1 7 - 2 6}$ & $\mathbf{2 7 - 3 9}$ & $\mathbf{4 0 - 4 9}$ & $\mathbf{5 0 +}$ \\
\hline High performance zone & $2880+$ & $2560+$ & $2400+$ & $2240+$ \\
\hline Good fitness zone & $2480-2779$ & $2320-2559$ & $2240-2399$ & $2000-2239$ \\
\hline Marginal zone & $2160-2479$ & $2080-2319$ & $2000-2239$ & $1760-1999$ \\
\hline Low zone & $<2160$ & $<2080$ & $<2000$ & $<1760$ \\
\hline
\end{tabular}

Adopted from Concept of physical fitness for wellness $10^{\text {th }}$ edition, Charles B, et al. (2000) 
The athletes have been tested and their tests have been recorded. While the athletes have been placed in to groups according to their position, they have also been given a playing status of either project participants or non-participants by central tendency statically analysis has been profound on each group. This analysis procedure is importance for each test for each group. This information would be used by the lower body strength and endurance professional. This information is a way to evaluate the tests being administered the athletes and this information is a way to evaluate lower body strength and endurance program.

\section{Results}

The purpose of this study was to examine the change in the results of three physical performance test between project participants and non-participant after implementing general and specific warming up program. Squat test were recorded in a number of counts in minute, step test were recorded in heart beats and 12-minuite run test were recorded in meter. Score of boys in under-17 youth football development project participants and non-participants according to row score norms in three performance tests variables were analyzed.

The results of the study was to examine the change in the results of three physical performance test between project participants and non-participant after implementing general and specific warming up program. Squat test were recorded in a number of counts in minute, step test were recorded in heart beats and 12-minuite run test were recorded in meter.

The analysis of Table 4, indicates that the mean, median, mode and range values for strength variable for boys in under-17 youth football development project participants were recorded $(48,50,51$, and 16$)$ frequency and non-participants recorded $(38.8,36,34$, and 20$)$ frequency respectively. It shows that boys in under-17 youth football development project participants have performed better as compared to their non-participants in strength variables. As table has been observed that mean, median, mode and range score of project participants is higher than non-participants. We come to the conclusion that boys in under-17 youth football development project participants have better strength than non-participants.

The analysis of Table 5 indicates that the mean, median, mode and range values for step test variables for boys in under-17 youth football development. Boys in under-17 youth football development project participants were recorded 989, 90, 96 and 24) heartbeat and non-participants recorded 994, 92, 90 and 27) heartbeat respectively. This shows that boys in under-17 youth football development project participants have performed better as compared to their non-participant in heartbeat variables.

Table 5 has been observed that the mean, median, mode and range score of boys in under-17 youth football development project participants is higher than non-participants as compared participants. From the above raw data we deduce that boys in under-17 youth football development project participants have better heart (lower heart) beat than non-participants.

The analysis of Table 6 show that the mean, median, mode and range value of 12 -minutes run test variables for boys in under-17 youth football development project participants and non-participants were recorded $2608 \mathrm{~m}, 2640 \mathrm{~m}, 2600 \mathrm{~m}, 660 \mathrm{~m}$ and $2466 \mathrm{~m}, 2450 \mathrm{~m}$, $2430 \mathrm{~m}, 680 \mathrm{~m}$ respectively. This revels that boys in under-17 youth football development project participants run longer distance than non-participants in 12-minutes. From the above table we have been observed that the mean, median, mode and range score of boys in under-17 youth football development project participants is higher than non-participants.

According to row score on Table 7 norms of boys in under-17 youth football development project participants personal best score found in excellent, good and above average zone but non-participants score founded good zone up to poor zone. Thus overall, we can say

Table 4: Comparative analysis of strength between project participants \& non-participants.

\begin{tabular}{|l|l|l|l|l|l|l|}
\hline Group & Sample & Mean & Median & Mode & Range & Unit \\
\hline Project participants & 25 & 48 & 50 & 51 & 16 & No of counts \\
\hline Non-participants & 25 & 38.8 & 36 & 34 & 20 & \\
\hline
\end{tabular}

Table 5: Comparative analysis of step test between project participants and non-participants.

\begin{tabular}{|l|l|l|l|l|l|l|}
\hline Group & Sample & Mean & Median & Mode & Range & Unit \\
\hline Project participants & 25 & 89 & 90 & 96 & 24 & Heart beats \\
\hline Non-participants & 25 & 94 & 92 & 90 & 27 & \\
\hline
\end{tabular}

Table 6: Comparative analysis of 12-minute between under-17 youth football development project and non- participants.

\begin{tabular}{|l|l|l|l|l|l|l|}
\hline Group & Sample & Mean & Median & Mode & Range & Unit \\
\hline Project participants & 25 & 2608 & 2640 & 2600 & 660 & Meter \\
\hline Non-participants & 25 & 2466 & 2450 & 2430 & 680 \\
\hline
\end{tabular}


Table 7: Raw score norms for squat test.

\begin{tabular}{|c|c|c|c|c|c|c|}
\hline \multirow[t]{2}{*}{ No } & \multirow[t]{2}{*}{ Classification } & \multirow[t]{2}{*}{ Score } & \multicolumn{2}{|l|}{ Project participants } & \multicolumn{2}{|l|}{ Non-participants } \\
\hline & & & No of Participants & $\%$ & No of Participants & $\%$ \\
\hline 1 & Excellent & $>49$ & 13 & 52 & - & - \\
\hline 2 & Good & $44-49$ & 7 & 28 & 7 & 28 \\
\hline 3 & Above average & $39-43$ & 5 & 20 & 3 & 12 \\
\hline 4 & Average & $35-38$ & - & - & 5 & 20 \\
\hline 5 & Below average & $31-34$ & - & - & 8 & 32 \\
\hline 6 & Poor & $25-30$ & - & - & 2 & 8 \\
\hline 7 & Very poor & $<25$ & - & - & - & - \\
\hline \multicolumn{3}{|c|}{ Total } & 25 & 100 & 25 & 100 \\
\hline
\end{tabular}

Table 8: Raw score norms for step test.

\begin{tabular}{|c|c|c|c|c|c|c|}
\hline \multirow[t]{2}{*}{ No } & \multirow[t]{2}{*}{ Classification } & \multirow[t]{2}{*}{ Score } & \multicolumn{2}{|l|}{ Project participants } & \multicolumn{2}{|l|}{ Non-participants } \\
\hline & & & No of Participants & $\%$ & No of Participants & $\%$ \\
\hline 1 & High performance zone & 84 or less & 6 & 24 & - & - \\
\hline 2 & Good fitness zone & $85-95$ & 13 & 52 & 16 & 64 \\
\hline 3 & Marginal zone & 96-119 & 6 & 24 & 9 & 36 \\
\hline 4 & Low zone & $120 \&$ above & - & - & - & - \\
\hline \multicolumn{3}{|c|}{ Total } & 25 & 100 & 25 & 100 \\
\hline
\end{tabular}

Table 9: Raw score norms for 12-minut run test.

\begin{tabular}{|l|l|l|l|l|l|l|}
\hline No & Classification & Score & Project participants & \multicolumn{2}{l|}{ Non-participants } \\
\cline { 4 - 7 } & & & No of Participants & $\%$ & No of Participants & \% \\
\hline 1 & High performance zone & $2880+$ & - & - & - & - \\
\hline 2 & Good fitness zone & $2480-2779$ & 20 & 80 & 12 & 48 \\
\hline 3 & Marginal zone & $2160-2479$ & 5 & 20 & 12 & 48 \\
\hline 4 & Low zone & $<2160$ & - & - & 1 & 4 \\
\hline Total & & & $\mathbf{2 5}$ & $\mathbf{1 0 0}$ & $\mathbf{2 5}$ & 100 \\
\hline
\end{tabular}

that strength of boys in under-17 youth football development project participants were better than non-participants.

According to row norms of Table 8 the project participants personal best score found in high performance zone, good fitness zone and marginal, but non-participant personal score found only good fitness zone and marginal zone. So, we can say project participants have better (lower heart) beats than non-participants.

According to raw score norms of Table 9 project participants more personal score found good fitness zone and marginal, but non-participants personal score found in good fitness zone, marginal zone and low zone. So, we simply deduce that project participants have better score in 12-minute run test than non-participants.

\section{Discussion}

The purpose of this study was to examine the change in the results of three physical performance test between project participants and non-participant after implementing general and specific warming up program. Squat test were recorded in a number of counts in min- ute, step test were recorded in heart beats and 12-minuite run test were recorded in meter. Score of boys in under-17 youth football development project participants and non-participants according to row score norms in three performance tests variables were analyzed.

Physical fitness is a multidimensional state of being. It is the body ability to function efficiently and effectively. According to [3] physical fitness is a state of being that consists of at least five health-related and six skill-related physical fitness components, each of which contributes to total quality of life. Level of fitness depends on such physiological factors such as the heart ability to pump blood and the size muscle fiber.

To develop fitness, a person must perform enough physical activity to stress the body and cause long term physiological changes. [6] found that physical fitness is not a static factor and it varies from individual to individual and in the same person from time to time depending on factors. According to [7], it was the desire to establish a scientific approach to the development of physical fitness. The United States president's Council on physical fitness and sports defined the terms "physical fitness 
as the ability to carry out daily task with vigor and alertness, without undue fatigue, with ample energy to enjoy leisure time pursuits and to meet unforeseen emergencies" [8].

Some conditioning programs aimed at improving sport performance, may reduce the risk disease this is not their primary purpose. [9] Suggested that the single goal of sport conditioning is to improve physical performance in a specific sport. However, the weekend athlete who engages in a total health related physical fitness program could also improve his or her physical performance in many sports. Specifically, a health-related fitness program improves sport performance by increasing muscular strength and endurance, improving flexibility and reducing the risk of injury.

According to [10] physical fitness is a set of physical attributes that allows the body to respond or adapt to the demand and stress of physical effort to perform moderate to vigorous level of physical activity without becoming over tired. [3] Suggests that, specialized forms of training are needed to optimize adaptations to exercise and performance in sports. Fitness is needed for success in many sports. According to [10], skill-related fitness refers to a group of basic abilities that helps you perform well in sports and activities requiring certain physical skills.

Physical fitness variables are very important in both athletes and form a condition for higher performance. [11] Stated that the components of physical fitness like strength, speed, endurance flexibility and the various co-coordinative abilities are essential for a high technique and tactical efficiency. Depending upon the demand of the game each factor of physical fitness should be optimally developed.

The performance of sportsman in any game or events are depends on physical fitness. The physical fitness or condition is the sum total of five motor abilities namely muscular strength, agility, power, speed and cardiovascular endurance. Therefore, the sports performance in all sports depends to great extent on these abilities. Improvement and maintenance of physical fitness is the most important aim of sports training. According to [12] Physical fitness is very important concept of physical education and can't be neglected. It is very important determinant [13], for a high level of efficiency in techniques and tactics in most sports; a high level of physical fitness is most important. So for making selection in sports physical fitness is the most important factor and can't be neglected. In association with the finding of the study [3] suggests that the increase in size and power allows the heart to pump a greater volume of blood with fewer strokes per minute. For example, the average individual has a resting heart rate between 70 and 80 beats per minute, whereas it is not uncommon for trained athletes pulse to be in the low 50 s or even in the 40 s.
[3] suggested that, trained heart is more efficient and subject to less stress. It pumps more blood per beat, so heart rate is lower at rest and during exercise. The resting heart rate of a fit person is often 10-20 beats per minute lower than that of untrained person. [3] also strengthens a fast time and low heart rate indicates a high level of cardiovascular endurance. From the above table we have been observed that the mean, median, mode and range score of boys in under- 17 youth football development project participants is higher than non-participants.

[14] Suggested that having muscular strength can keep you from being easily fatigued. Strong muscle also help you stand, sit, and walk easily. Muscular strength improves performance in sports. Thus overall, we can say that strength of boys in under-17 youth football development project participants were better than non-participants [3]. A person with moderate to high level of muscular strength and endurance can perform daily tasks easily and people with poor muscle strength tire more easily and are less effective in activities. Therefore, anyone simply concludes that boys in under-17 football development project participants have better performing strength than non-participants. [15] Made a comparative study of physical variable (muscular strength) football players \& athletes of school levels. They found that there were no significant difference was found in football players and athletes of school level in regards of muscular strength variable. But this study found that there was a significant difference variable of physical qualities (lower body strength and endurance) between under-17 youth football development project and Non-athlete.

\section{Conclusion}

- The study confirms the fact that boys in under-17 youth football development project participants are comparatively better lower body strength and endurance than non-participants.

- In conclusion results of the study confirmed that boys under-17 youth football development project participants are comparatively better cardiovascular endurance than non-athlete.

- Five football project participants squat test scores were found above average zone.

- Six football project participants step test scores were found marginal zone.

- Five football project participants' 12 -minute run test score were found in marginal zone.

\section{Acknowledgement}

The authors give special thanks to Berhanu Tesema (Assistant Professor) for his generous contribution and valuable comments on this article. 


\section{References}

1. Grahm J (1994) Guidelines for providing valid testing of athletes' fitness levels, strength and endurance. USA, 64-70.

2. Ebben WP (1998) Review of football fitness testing and evaluation. Strength and Conditioning. USA. Olympic Educational Center 20: 42-49.

3. Charles B, et al. (2015) Concept of Physical Fitness. Active lifestyle for wellness. (10 ${ }^{\text {th }}$ edn), Mc Graw-Hill Higher Education. USA, 106.

4. Maurya DC, Kumar R, Suri SS (2015) A comparative study of Physical variable (Muscular strength) football players and athletes of school levels. 3: 1-4.

5. Di Salvo, Baron R, Tschan H, Calderon Montero FJ, Bachl N, et.al. (2007) Performance characteristics according to playing position in elite soccer. Int J Sports Med 28: 222227.

6. Clarke HH, Clarke DH (1989) Application of measurement Health and Physical Education, Prentice-Hall Inc., Englewood Cliffs, New Jersey, USA, 3-10.

7. Nixon E (1964) An introduction to physical education W.B Saunders Company, Philadelphia. USA, 201-205.
8. Clarke HH (1971) Physical and motor tests in the Medford Boys' Growth Study, Englewood Cliffs, NJ: Prentice-Hall, 187-191.

9. ACSM's Guidelines for Exercise Testing and Prescription (2006) $\left(7^{\text {th }}\right.$ edn), Philadelphia: Lippencott, Williams \& Wilkins. USA, 82-90.

10. Thomas D, et al. (2001) Feet and well ( $4^{\text {th }}$ edn), core concept and labs in physical fitness and Wellness Mayfield Publishing Company. USA, 45-70.

11. Mal B (1982) Scoring ability in football. SNIPES J.P. 22-23.

12. Uppal AK (1980) Effects of 10 weeks participation in physical education program on selected strength variables in women. SNIPES 3: 31-34.

13. Harre D (1979) Training Slehre, sports verlag Berlin.

14. Linda, Meeks, Philip Heit (1991) Health a wellness Approach. Merrill publishing company. USA 96-102.

15. Reddy JM (2012) Comparison of Circuit Training Methods on Performance Variables of Sc/St Non-Sc/St Boys. International Journal of Multidisciplinary Research 2: 221. 